\title{
Estimation of typical food portion sizes for children of different ages in Great Britain
}

\author{
Wendy L. Wrieden ${ }^{1 *}$, Patricia J. Longbottom ${ }^{1}$, Ashley J. Adamson ${ }^{2}$, Simon A. Ogston ${ }^{3}$, Anne Payne ${ }^{4}$, \\ Mohammad A. Haleem ${ }^{1}$ and Karen L. Barton ${ }^{1}$ \\ ${ }^{1}$ Centre for Public Health Nutrition Research, Division of Medicine and Therapeutics, University of Dundee, Ninewells Hospital \\ and Medical School, Dundee DD1 9SY, UK \\ ${ }^{2}$ Human Nutrition Research Centre, School of Clinical Medical Sciences, University of Newcastle upon Tyne, William Leech \\ Building, Framlington Place, Newcastle upon Tyne NE2 4HH, UK \\ ${ }^{3}$ Section of Public Health, Division of Community Health Sciences, University of Dundee, McKenzie Building, Kirsty Semple Way, \\ Dundee DD2 $4 B F, U K$ \\ ${ }^{4}$ School of Health Professions, Faculty of Health and Social Work, University of Plymouth, Peninsula Allied Health Centre, \\ Derriford Road, Plymouth PL6 8BH, UK
}

(Received 20 December 2006 - Revised 1 October 2007 - Accepted 10 October 2007 - First published online 22 November 2007)

It is often the case in dietary assessment that it is not practicable to weigh individual intakes of foods eaten. The aim of the work described was to estimate typical food portion weights for children of different ages. Using the data available from the British National Diet and Nutrition Surveys of children aged $1 \frac{1}{2}-4 \frac{1}{2}$ years (1992-1993) and young people aged 4-18 years (1997), descriptive statistics were obtained, and predicted weights were calculated by linear, quadratic and exponential regression for each age group. Following comparison of energy and nutrient intakes calculated from actual (from an earlier weighed intake study) and estimated portion weights, the final list of typical portion sizes was based on median portion weights for the 1-3- and 4-6-year age groups, and age-adjusted means using linear regression for the 7-10-, 11-14- and 15-18-year age groups. The number of foods recorded by fifty or more children was 133 for each of the younger age groups (1-3 and 4-6 years) and seventy-five for each of the older age groups. The food portion weights covered all food groups. All portion sizes increased with age with the exception of milk in tea or coffee. The present study draws on a unique source of weighed data on food portions of a large sample of children that is unlikely to be repeated and therefore provides the best possible estimates of children's food portion sizes in the UK.

\section{Food portion sizes: Children: UK}

Accurate energy and nutrient intakes can only be estimated if an accurate portion size of each food consumed is available alongside appropriate compositional data. Portion sizes can be difficult to obtain in both children and adults because descriptions in the absence of food scales are reliant on conceptualisation of food portion sizes.

Although average portion size data, derived from weighed dietary surveys, are available in the $\mathrm{UK}^{(1)}$ no such data are available for children. Although not advised for use in assessing individual diets, these average portions are useful for pooled data of normal healthy individuals and have provided the data for tools to estimate individual food portion size such as the Photographic Atlas of Food Portion Sizes ${ }^{(2)}$.

Most surveys of children's diets have been carried out using a variety, or combination, of methods to estimate food portion size, adding an extra burden to both researcher and participants. Thus food models, photographs and household measures have been used. In the absence of age-appropriate portion size data many of these tools have been based on adult portion sizes and could potentially introduce considerable error. Livingstone \& Robson $^{(3)}$ point out, 'the assumption that inclusion of any quantification tool will improve the estimation capabilities of children has not been verified.' Thus it seems that no dietary assessment method is perfect, but practical considerations are an important part of improving compliance to study procedures. A list of typical food portions would therefore provide a useful tool in devising food portion estimation tools for the assessment of diets for children of different age groups.

The British National Diet and Nutrition Survey (NDNS) collected weighed intake data from nationally representative samples of 1675 children aged $1 \frac{1}{2}-4 \frac{1}{2}$ years $^{(4)}$ and 1701 young people aged $4-18$ years ${ }^{(5)}$ and thus provides the only large database from which the average portion sizes eaten by British children can be estimated. As food portion size will normally increase with age and, indeed, may be greater in the mid-teens than in adulthood due to higher energy demands ${ }^{(6)}$,

Abbreviation: NDNS, British National Diet and Nutrition Survey.

* Corresponding author: Dr Wendy L. Wrieden, fax + 441382 496452, email w.1.wrieden@dundee.ac.uk 
children's portion sizes must be calculated separately for the different age ranges. For comparison of the energy and nutrient intakes with recommendations it is convenient if these age ranges match those used for the UK dietary reference values $^{(6)}$, namely $1-3,4-6,7-10,11-14$ and $15-18$ years.

The overall aim of the present study was to produce and test a set of typical food portion weights for children of ages $1-3$, $4-6,7-10,11-14$ and $15-18$ years using food portion information from the recent dietary surveys of children (NDNS of children aged $1 \frac{1}{2}-4 \frac{1}{2}$ years and of young people aged 4-18 years).

\section{Methods}

Using the data available from the NDNS of children, average portion weights for different age groups were calculated. These were then substituted for actual weights in weighed food diaries of children surveyed in previous studies at the Universities of Dundee ${ }^{(7,8)}$ and Edinburgh ${ }^{(9)}$, and results of average energy and nutrient intakes were compared with those estimated using the actual portion weights.

The databases from the two NDNS surveys were obtained from the Data Archive at the University of Essex. Individual records on weights of food eaten (i.e. weight served minus leftovers) were extracted and merged with demographic information, for example, age and sex using Microsoft Access. Children were grouped according to the age ranges of the UK dietary reference values ${ }^{(6)}$, namely $1-3,4-6,7-10$, $11-14$ and 15-18 years. Food portion information was examined and foods eaten by $\geq 1 \%$ of all children were identified. These foods were then grouped by similar type and composition (for example, flake cereals consisted of the market leader for cornflakes and bran flakes, plus supermarket own brands) and a list was compiled of these grouped foods eaten by $\geq 2 \%$ of all children. Typical portion sizes were calculated for all foods consumed by $\geq 10 \%$ of all children. Typical portion sizes for foods consumed by only 2-9.9\% of all children were also calculated but were recorded as estimates. As some foods have different portion weights depending on the form in which they are weighed (for example, oranges with or without peel), it was necessary to apply a factor to some weights in order to report them in the same form as the majority of weights in the food grouping. This was done using standard published factors ${ }^{(10-13)}$. Food groupings were allocated a new code and food name in order to ease future calculations. Different codes (where number of consumers permitted) were allocated to foods likely to have different serving sizes dependent on the mode of use. Examples of these are: milk on cereal; milk as a drink; milk in tea or coffee; milk in a hot milky drink; cheese (average); cheese on bread; cheese on toast; baked beans (average); baked beans on toast.

The mean portion weight of each subject's consumption of each of the foods was calculated. This was carried out so that each subject contributed a single portion weight, thus avoiding the possibility that someone who always ate large or small portions could skew the results due to a high frequency of eating occasions. The data were then transferred to SPSS (versions 10-14; SPSS, Inc., Chicago, IL, USA) for further analysis. Distribution curves were produced for each food by age group. For the purposes of the present study all weights recorded were included unless they were less than $1 \mathrm{~g}$. Thus the average portion encompasses the full range of possibilities including, for example, one crisp or pea. Statistical comparisons (parametric and non-parametric) were made for the portion sizes calculated for both boys and girls to assess if there was a need to report them separately. For each age group descriptive statistics were obtained, and predicted weights were calculated by linear, quadratic and exponential regression. The predicted values enabled portion weights to be estimated for age groups where $<2 \%$ of children consumed the food but, for the purposes of the present paper, weights are only given where the food was eaten by at least fifty subjects in each age group. Non-consumers were excluded from the portion size analysis.

The testing of the use of the calculated typical portion sizes has been summarised in an abstract ${ }^{(14)}$ and will be reported in full in due course. In brief, fifty weighed food diaries collected for previous studies, from each of the three age ranges, $1-3$, 4-6 and 11-14 year-old (no such data were available for the other age groups) were re-analysed for energy and nutrients using the actual and five calculated weights (mean, median, age-adjusted by linear, quadratic and exponential regression) for each food. Paired $t$ tests were then used to detect significant differences in energy and each nutrient, derived from actual and calculated portion weights. The number of weighed food diaries analysed was a pragmatic choice based on availability and quality of the data. As the purpose of the study was to ascertain which calculation of portion size was most appropriate for each age group, any comparisons that showed significant differences were discarded. Where no statistical difference was apparent Bland-Altman plots were carried out to assess level of agreement ${ }^{(15)}$.

\section{Results}

A total of 3374 weighed dietary records from the two NDNS provided data from which to extract portion weights. The number of children in each of the age groups $1-3,4-6,7-10$, 11-14 and 15-18 years was 1457, 574, 481, 475 and 387 respectively, hence the minimum number of weighed records used to calculate an average portion weight for an age group was thirty-eight ( $10 \%$ of the total).

Paired $t$ tests on the data showed that the energy and nutrients calculated from median portion weights for the 1-3-year age group, median and age-adjusted linear regression for the 4-6-year age group and mean and age-adjusted linear regression for the 11-14-year age group gave no significant differences from those calculated using actual weights. All other estimated portion weights gave some nutrient values that were significantly different from those calculated using actual portion weights. Bland-Altman plots (for examples, see Figs. 1 and 2) to assess agreement, displaying the differences between the values calculated using the actual and the estimated weights, showed that the mean differences were small and that most of the individual values lay within 2 standard deviations of the mean. The final list of typical children's portion sizes was based on median portion weights for the 1-3and 4-6-year age groups and age-adjusted linear regression for the 7-10-, 11-14- and 15-18-year age groups.

The number of foods recorded by fifty or more children is higher for the younger age groups (1-3 and 4-6 years) due to a larger sample size. Table 1 presents median portion sizes for 133 foods. Only seventy-five foods were eaten by 


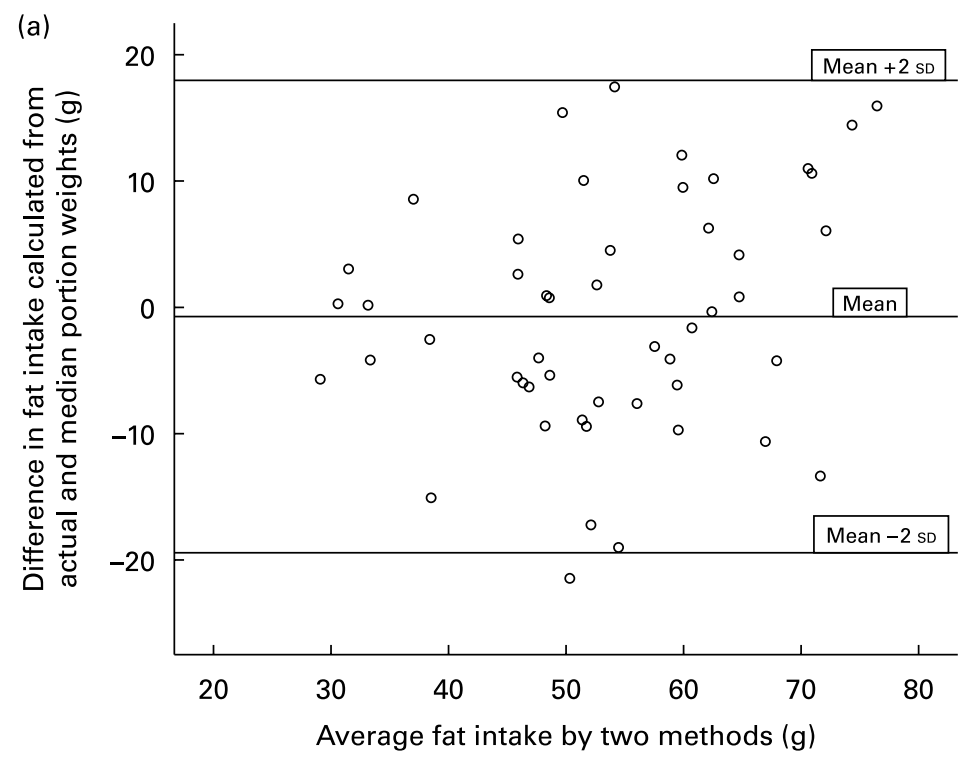

(b)

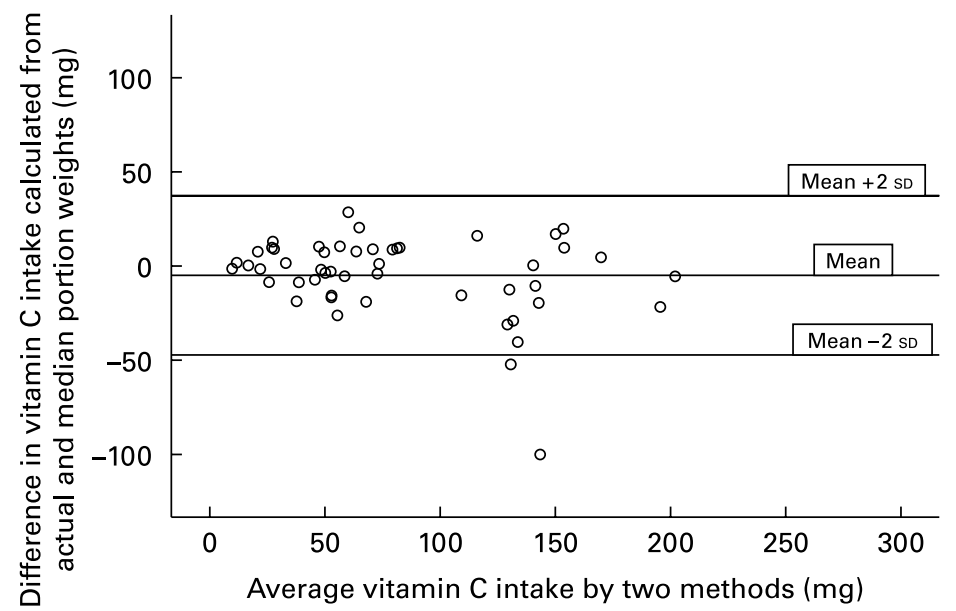

Fig. 1. Bland-Altman plots for fat (a) and vitamin C (b) intakes derived from actual and median calculated portion sizes for children aged 4-6 years.

fifty or more children in each of the older age groups and the age-predicted portion weights of these are reported in Table 2. The food portion weights presented in Tables 1 and 2 cover all food groups, including pasta, rice, pizza, bread, breakfast cereals, biscuits, cakes (1-6-year-old only), puddings (1-6-yearold only), milk (served in various forms), cheese, yogurt, eggs, meat, meat dishes, fish, vegetables (including potatoes in different forms), fruit, crisps and savoury snacks, chocolate and sugar confectionery, and beverages. Differences in food portion weights between boys and girls were seen for a small number of foods but these were not consistent across the age range, therefore typical portion weights are reported by age group but not by sex. At worst twenty-eight out of the seventy-five food portion sizes reported for the 15-18year-old showed significant differences between girls and boys when using both non-parametric and parametric comparisons. However, the linear regression for this age group was run for the combined group of boys and girls, as the majority of foods showed no significant differences between sexes.
The number of foods reported for this group would have been considerably lower if sex-specific portion sizes were given due to reduced sample size.

All portion sizes increased with age with the exception of milk in tea or coffee.

\section{Discussion}

Results from two large national dietary surveys provided a suitable database to calculate the typical food portion sizes of over 100 different foods. These portion sizes were shown to give similar mean results in nutritional analyses to using actual weights in fifty weighed food diaries from each of the age groups $1-3,4-6$ and $11-14$ years. Details of the surveys that these data were originally collected for have been published ${ }^{(7-9)}$ and although all tended to have a slightly higher proportion of girls than boys the samples covered all socioeconomic groups and can be considered a representative sample of the population. In both the NDNS and these dietary 

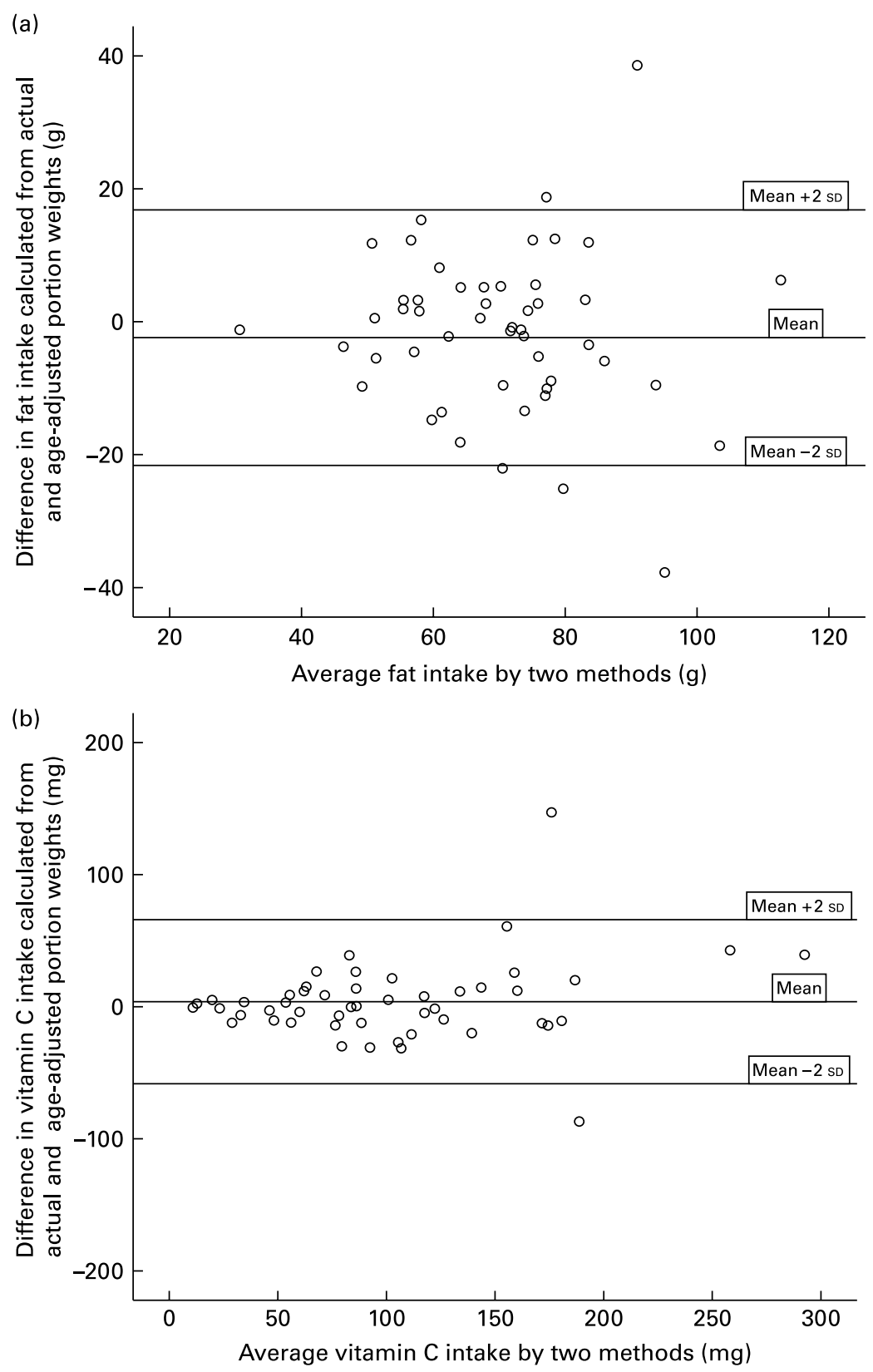

Fig. 2. Bland-Altman plots for fat (a) and vitamin C (b) derived from actual and linear predicted calculated portion sizes for children aged $11-14$ years.

surveys about half of the participants had a head of household in a non-manual occupation ${ }^{(4,5,8)}$ or with university entrance qualifications $^{(7)}$ or were in the most affluent deciles for a multiple index of deprivation.

No method of dietary assessment is perfect and the weighed intake method, despite being considered as the most precise method for estimating food and nutrient intake, is still subject to underreporting and is unsuitable for those who lack motivation or have poor numeracy and literacy skills ${ }^{(16)}$. Thus the food portions reported and the diaries used to test the data may not be representative of this group of the population. Nevertheless in the absence of anything else, the data provided in the present study are likely to provide some useful guidance for those who aim to assess children's food intake.
Using linear regression to predict portion weights for age groups where data were limited has allowed the assignment of typical portion weights for the whole age range. However, in the present study the data reported are limited to those calculations based on fifty subjects eating the particular food in each age group. This was a pragmatic choice but provides the reader with robust estimates as indicated by the CI given in Table 2 . Despite higher intakes of energy intake by 15 -18-year-old boys compared with girls ${ }^{(5)}$ less than half of the median portion sizes were significantly different when boys and girls were compared. It was therefore decided to report a combined portion size for all foods and thus avoid reducing the number of items available due to the smaller sample size that would be obtained if the food portions were reported separately for boys and girls. 
Table 1. Median portion sizes ( $\mathrm{g}$ ) and interquartile ranges (IQR) of a variety of foods consumed by children aged 1-3 and 4-6 years

\begin{tabular}{|c|c|c|c|c|c|c|}
\hline \multirow{2}{*}{$\begin{array}{l}\text { Age range (years)... } \\
\text { Food group }\end{array}$} & \multicolumn{3}{|c|}{$1-3(n 1457)$} & \multicolumn{3}{|c|}{$4-6(n 574)$} \\
\hline & $n$ & Median & IQR & $n$ & Median & IQR \\
\hline \multicolumn{7}{|l|}{ Pasta and rice } \\
\hline Pasta, boiled & 337 & 63 & $37-94$ & 202 & 84 & $52-118$ \\
\hline Pasta, canned in sauce & 458 & 86 & $50-126$ & 214 & 84 & $51-125$ \\
\hline Rice, boiled & 172 & 50 & $30-77$ & 124 & 77 & $45-100$ \\
\hline \multicolumn{7}{|l|}{ Pizza } \\
\hline Pizza, thin base & 121 & 60 & $35-93$ & 119 & 82 & $58-106$ \\
\hline \multicolumn{7}{|l|}{ Other cereals } \\
\hline Yorkshire pudding & 253 & 22 & $11-42$ & 117 & 35 & $20-51$ \\
\hline \multicolumn{7}{|l|}{ Breads } \\
\hline Bread, white and softgrain, sliced & 994 & 31 & $22-42$ & 464 & 46 & $36-61$ \\
\hline Bread, wholemeal, brown and granary, sliced & 486 & 30 & $20-42$ & 164 & 48 & $30-61$ \\
\hline Bread, white and softgrain, toasted & 821 & 25 & $17-34$ & 342 & 35 & $27-48$ \\
\hline Bread, wholemeal, brown and granary, toasted & 252 & 21 & $14-29$ & 59 & 30 & $20-47$ \\
\hline Bread, rolls, white & 351 & 34 & $21-46$ & 232 & 45 & $39-55$ \\
\hline Bread, white, crusty & 167 & 28 & $16-41$ & 84 & 46 & $28-60$ \\
\hline Crumpets/pikelets/Scotch pancakes & 125 & 35 & $25-49$ & 60 & 54 & $39-80$ \\
\hline \multicolumn{7}{|l|}{ Breakfast cereals } \\
\hline Rice Krispie-type cereals & 428 & 18 & $11-26$ & 223 & 24 & $17-34$ \\
\hline Flake cereals & 434 & 19 & $11-26$ & 182 & 24 & $17-33$ \\
\hline Weetabix & 532 & 19 & $15-27$ & 178 & 25 & $18-38$ \\
\hline Coated cornflakes & 229 & 21 & $14-30$ & 155 & 30 & $21-36$ \\
\hline Sugar-puffed cereals & 152 & 19 & $12-26$ & 72 & 26 & $18-32$ \\
\hline Hoop or loop cereals & 112 & 20 & $12-27$ & 70 & 30 & $22-38$ \\
\hline \multicolumn{7}{|l|}{ Biscuits } \\
\hline Sandwich biscuits & 468 & 16 & $12-24$ & 192 & 21 & $14-27$ \\
\hline Chocolate biscuits, fully coated sandwich & 287 & 24 & $18-25$ & 167 & 24 & $22-26$ \\
\hline Short sweet biscuits & 348 & 14 & $9-22$ & 134 & 17 & $9-24$ \\
\hline Digestive-type biscuits & 239 & 15 & $13-23$ & 114 & 21 & $14-30$ \\
\hline Chocolate biscuits, fully coated biscuit only & 148 & 20 & $14-23$ & 86 & 24 & $19-26$ \\
\hline Digestives, half-coated chocolate & 140 & 17 & $13-25$ & 74 & 25 & $17-32$ \\
\hline Ice-cream wafer & 145 & 5 & $3-5$ & 78 & 3 & $3-4$ \\
\hline Cheese-flavoured biscuits & 113 & 17 & $9-29$ & 66 & 26 & $16-31$ \\
\hline Cookies & 122 & 14 & $10-22$ & 85 & 20 & $15-30$ \\
\hline Crackers & 107 & 9 & $7-16$ & 71 & 16 & $11-22$ \\
\hline \multicolumn{7}{|l|}{ Buns, cakes and pastries } \\
\hline Sponge sandwich cake with filling (sponge made with fat) & 132 & 35 & $23-52$ & 79 & 45 & $28-60$ \\
\hline Fairy/fancy cakes & 124 & 28 & $21-40$ & 98 & 36 & $28-55$ \\
\hline Chocolate mini rolls & 80 & 26 & $23-28$ & 51 & 27 & $25-31$ \\
\hline Chocolate cake/gateau (sponge made without fat) & 78 & 30 & $24-46$ & 66 & 45 & $31-64$ \\
\hline Slab cakes & 79 & 33 & $23-44$ & 50 & 43 & $27-60$ \\
\hline Doughnuts, jam and iced & 69 & 50 & $37-69$ & 67 & 70 & $55-75$ \\
\hline \multicolumn{7}{|l|}{ Yogurts, desserts and puddings } \\
\hline Yogurt & 526 & 119 & $90-128$ & 207 & 122 & $100-133$ \\
\hline Ice-cream & 473 & 49 & $33-64$ & 238 & 60 & $46-75$ \\
\hline Fromage frais & 348 & 53 & $43-61$ & 174 & 52 & $44-61$ \\
\hline Dairy desserts & 163 & 60 & $48-78$ & 90 & 63 & $56-90$ \\
\hline Custard & 139 & 79 & $50-112$ & 98 & 90 & $75-120$ \\
\hline Jelly & 140 & 80 & $44-119$ & 82 & 114 & $64-126$ \\
\hline Choc ice & 94 & 42 & $36-45$ & 59 & 48 & $39-56$ \\
\hline Milk and cream & & & & & & \\
\hline Milk on cereal & 1268 & 80 & $54-107$ & 524 & 101 & $73-130$ \\
\hline Milk as a drink & 1093 & 136 & $103-178$ & 419 & 153 & $118-192$ \\
\hline Milk in tea or coffee & 576 & 54 & $32-79$ & 196 & 49 & $30-69$ \\
\hline Milk in a hot milky drink & 118 & 129 & $94-181$ & 110 & 172 & $118-202$ \\
\hline Cheese & & & & & & \\
\hline Hard cheese & 656 & 19 & $12-27$ & 285 & 25 & $17-37$ \\
\hline Hard cheese on bread & 361 & 20 & $11-27$ & 180 & 25 & $17-36$ \\
\hline Hard cheese on toast & 116 & 25 & $14-36$ & 54 & 34 & $21-46$ \\
\hline Cheese spread & 215 & 13 & $7-16$ & 96 & 15 & $12-23$ \\
\hline Processed cheese & 75 & 18 & $11-25$ & 81 & 21 & $18-25$ \\
\hline Eggs and egg dishes & & & & & & \\
\hline Eggs, boiled & 287 & 50 & $31-58$ & 119 & 50 & $30-60$ \\
\hline Eggs, fried/poached & 222 & 40 & $24-54$ & 107 & 50 & $42-60$ \\
\hline Butter, margarine and spreads & & & & & & \\
\hline Soft margarine and low-fat spread & 1191 & 5 & $3-7$ & 482 & 7 & $5-9$ \\
\hline Butter & 410 & 5 & $3-8$ & 177 & 8 & $5-11$ \\
\hline Meat and meat products and alternatives & & & & & & \\
\hline Sausages & 588 & 42 & $24-57$ & 297 & 50 & $36-68$ \\
\hline
\end{tabular}


Table 1. Continued

\begin{tabular}{|c|c|c|c|c|c|c|}
\hline \multirow{2}{*}{$\begin{array}{l}\text { Age range (years)... } \\
\text { Food group }\end{array}$} & \multicolumn{3}{|c|}{$1-3(n$ 1457) } & \multicolumn{3}{|c|}{$4-6(n 574)$} \\
\hline & $n$ & Median & IQR & $n$ & Median & IQR \\
\hline Cooked chicken/turkey & 565 & 28 & $16-47$ & 241 & 47 & $30-69$ \\
\hline Ham & 387 & 18 & $11-26$ & 222 & 23 & $16-38$ \\
\hline Roast meat & 343 & 24 & $12-38$ & 122 & 41 & $23-65$ \\
\hline Burgers & 215 & 36 & $23-44$ & 105 & 42 & $36-64$ \\
\hline Bacon & 192 & 15 & $9-24$ & 103 & 25 & $15-42$ \\
\hline Frankfurters & 184 & 42 & $26-56$ & 80 & 48 & $33-70$ \\
\hline Sausage rolls & 192 & 54 & $34-70$ & 101 & 60 & $49-70$ \\
\hline Chicken/turkey nuggets/fingers/goujons & 140 & 47 & $32-67$ & 197 & 61 & $42-75$ \\
\hline Meat pies, including chicken & 134 & 54 & $32-86$ & 74 & 86 & $65-116$ \\
\hline Processed cold meat & 103 & 22 & $13-34$ & 56 & 25 & $18-38$ \\
\hline Chicken/turkey/vegetable burger & 84 & 36 & $20-59$ & 57 & 64 & $52-85$ \\
\hline \multicolumn{7}{|l|}{ Fish and fish products } \\
\hline Fish fingers & 342 & 43 & $28-56$ & 174 & 56 & $47-75$ \\
\hline Oily fish, canned & 162 & 23 & $15-40$ & 79 & 41 & $23-58$ \\
\hline Oily fish, canned on bread & 105 & 23 & $15-36$ & 66 & 36 & $22-56$ \\
\hline \multicolumn{7}{|l|}{ Vegetables } \\
\hline Carrots, raw & 141 & 20 & $10-33$ & 90 & 28 & $18-50$ \\
\hline Tomatoes, raw & 250 & 23 & $11-35$ & 139 & 32 & $20-42$ \\
\hline Cucumber, raw & 224 & 16 & $10-27$ & 171 & 22 & $14-30$ \\
\hline Lettuce, raw & 109 & 7 & $4-13$ & 104 & 15 & $9-20$ \\
\hline Carrots, boiled & 788 & 23 & $13-35$ & 336 & 34 & $21-45$ \\
\hline Baked beans in tomato sauce & 661 & 52 & $31-84$ & 317 & 70 & $45-91$ \\
\hline Baked beans in tomato sauce on toast & 136 & 74 & $40-105$ & 61 & 101 & $75-140$ \\
\hline Peas/mixed vegetables, boiled & 654 & 19 & $11-31$ & 268 & 30 & $19-43$ \\
\hline Cauliflower, boiled & 270 & 23 & $12-40$ & 118 & 37 & $21-60$ \\
\hline Cabbage, boiled & 239 & 19 & $10-35$ & 106 & 37 & $21-59$ \\
\hline Peas, processed & 205 & 25 & $15-38$ & 69 & 34 & $21-48$ \\
\hline Broccoli, boiled & 186 & 19 & $11-29$ & 124 & 35 & $23-51$ \\
\hline Sweetcorn, boiled & 182 & 20 & $12-32$ & 113 & 33 & $24-54$ \\
\hline Brussels sprouts, boiled & 161 & 18 & $9-31$ & 53 & 35 & $16-45$ \\
\hline Swede/turnip, boiled & 157 & 22 & $12-40$ & 60 & 30 & $18-40$ \\
\hline Runner beans, boiled & 94 & 15 & $7-25$ & 55 & 28 & $14-40$ \\
\hline \multicolumn{7}{|l|}{ Potatoes } \\
\hline Potato chips & 981 & 56 & $36-85$ & 458 & 79 & $56-102$ \\
\hline Roast potatoes & 423 & 36 & $18-57$ & 204 & 60 & $35-96$ \\
\hline Potatoes, old, boiled & 491 & 54 & $29-82$ & 204 & 82 & $51-113$ \\
\hline Potatoes, new, boiled & 358 & 49 & $28-74$ & 156 & 64 & $38-99$ \\
\hline Potatoes, old, mashed & 251 & 60 & $35-90$ & 170 & 85 & $52-120$ \\
\hline Potato waffles/fritters/hash browns & 156 & 39 & $25-54$ & 133 & 54 & $43-81$ \\
\hline Potatoes, old, baked, weighed with skin & 104 & 70 & $40-98$ & 81 & 100 & $69-152$ \\
\hline \multicolumn{7}{|l|}{ 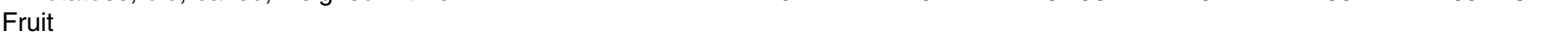 } \\
\hline Apples, eating, weighed with skin and core & 378 & 63 & $38-94$ & 292 & 96 & $63-109$ \\
\hline Apples, eating, flesh only & 324 & 50 & $32-75$ & 75 & 53 & $32-92$ \\
\hline Tangerines/mandarins/clementines/satsumas, flesh only & 224 & 49 & $37-65$ & 106 & 60 & $46-72$ \\
\hline Oranges, flesh only & 178 & 59 & $36-107$ & 61 & 87 & $50-115$ \\
\hline Bananas, flesh only & 677 & 68 & $47-88$ & 276 & 86 & $63-101$ \\
\hline Grapes & 223 & 42 & $25-63$ & 96 & 51 & $32-76$ \\
\hline Raisins/sultanas & 138 & 15 & $9-21$ & 63 & 17 & $14-25$ \\
\hline \multicolumn{7}{|l|}{ Fruit juice } \\
\hline Fruit juice & 492 & 110 & $77-140$ & 259 & 140 & $105-189$ \\
\hline \multicolumn{7}{|l|}{ Nuts and seeds } \\
\hline Peanut butter, smooth & 123 & 9 & $5-15$ & 62 & 12 & $8-18$ \\
\hline \multicolumn{7}{|l|}{ Sugar and preserves } \\
\hline Sugar, white & 699 & 4 & $2-5$ & 344 & 5 & $3-7$ \\
\hline Jam and marmalade & 444 & 8 & $4-11$ & 211 & 12 & $8-18$ \\
\hline Syrup and honey & 117 & 6 & $4-10$ & 59 & 9 & $6-14$ \\
\hline \multicolumn{7}{|l|}{ Sugar confectionery } \\
\hline Chew sweets & 234 & 18 & $12-34$ & 140 & 23 & $14-36$ \\
\hline Ice lollies & 214 & 45 & $30-60$ & 134 & 55 & $45-64$ \\
\hline Boiled sweets & 187 & 10 & $6-14$ & 122 & 10 & $5-17$ \\
\hline Sugar-coated jelly sweets & 184 & 34 & $17-40$ & 76 & 30 & $15-42$ \\
\hline Gum sweets & 110 & 21 & $10-35$ & 66 & 22 & $10-34$ \\
\hline Coated chew sweets & 123 & 30 & $16-48$ & 87 & 38 & $23-55$ \\
\hline Chocolate confectionery & & & & & & \\
\hline Chocolate with/without addition & 451 & 20 & $11-30$ & 247 & 20 & $12-32$ \\
\hline Kit Kat & 170 & 21 & $20-22$ & 135 & 22 & $21-26$ \\
\hline Coated small sweets & 315 & 25 & $14-36$ & 137 & 26 & $15-37$ \\
\hline Chocolate-covered caramel & 161 & 29 & $16-33$ & 96 & 26 & $18-43$ \\
\hline
\end{tabular}


Table 1. Continued

\begin{tabular}{|c|c|c|c|c|c|c|}
\hline \multirow{2}{*}{$\begin{array}{l}\text { Age range (years)... } \\
\text { Food group }\end{array}$} & \multicolumn{3}{|c|}{$1-3(n 1457)$} & \multicolumn{3}{|c|}{$4-6(n 574)$} \\
\hline & $n$ & Median & IQR & $n$ & Median & IQR \\
\hline Chocolate-covered caramel biscuit & 94 & 27 & $20-32$ & 62 & 31 & $28-45$ \\
\hline White chocolate & 248 & 20 & $12-31$ & 73 & 14 & $10-26$ \\
\hline \multicolumn{7}{|l|}{ Crisps, nuts and savoury snacks } \\
\hline Crisps & 712 & 25 & $17-28$ & 407 & 26 & $24-28$ \\
\hline Cereal-based snacks & 474 & 20 & $13-24$ & 224 & 21 & $18-25$ \\
\hline Potato rings & 195 & 29 & $15-30$ & 90 & 30 & $23-30$ \\
\hline Potato puffs & 179 & 19 & $13-20$ & 67 & 18 & $17-20$ \\
\hline \multicolumn{7}{|l|}{ Soups, savoury sauces and pickles } \\
\hline Soup & 251 & 125 & $82-181$ & 78 & 170 & $125-212$ \\
\hline Gravy, thickened & 730 & 30 & $17-45$ & 261 & 43 & $25-52$ \\
\hline Tomato ketchup & 396 & 7 & $5-12$ & 222 & 12 & $8-17$ \\
\hline Mayonnaise & 143 & 7 & $3-11$ & 95 & 11 & $8-15$ \\
\hline Gravy, unthickened & 131 & 27 & $14-45$ & 65 & 45 & $24-69$ \\
\hline Marmite & 173 & 2 & $1-3$ & 67 & 2 & $1-3$ \\
\hline \multicolumn{7}{|l|}{ Beverages } \\
\hline Tea, infusion & 543 & 86 & $59-114$ & 179 & 108 & $84-137$ \\
\hline Soft drinks, concentrated, not low energy & 900 & 30 & $23-40$ & 346 & 39 & $28-47$ \\
\hline Soft drinks, carbonated, not low energy & 659 & 145 & $109-187$ & 360 & 200 & $150-258$ \\
\hline Soft drinks, still, reconstituted (with and without sugar) & 428 & 200 & $142-250$ & 195 & 213 & $185-260$ \\
\hline Soft drinks, concentrated, low energy & 555 & 28 & $20-36$ & 306 & 36 & $28-45$ \\
\hline Soft drinks, carbonated, low energy & 195 & 130 & $103-171$ & 196 & 176 & $136-234$ \\
\hline Milkshake powder & 95 & 6 & $3-8$ & 68 & 10 & $6-14$ \\
\hline
\end{tabular}

One hundred and thirty-three foods are reported for the 1-3and 4-6-year age groups and seventy-five foods are reported for the 7-10-, 11-14- and 15-18-year age groups. These foods represent those most frequently reported in the NDNS of $1 \frac{1}{2}$ to $4 \frac{1}{2}$-year-old in 1992-1993 and 4-18-year-old in 1997. The portion weights of the most frequently reported foods together with portion information from packet foods will provide a tool for measuring nutrient intake in the absence of weighed food diaries but should be used with caution. It is important that the portion sizes reported are not simply used as default portion sizes as they are based on data that are now 13 and 9 years old and there are already data from the USA showing that portion sizes of specific foods, for example, soft drinks, hamburgers, and French fries have increased over the last 20 years ${ }^{(17,18)}$. However, some recent work from Liverpool, UK showed that although 9-10year-old children's selection of fruit and vegetable portions were subject to a large variation, the median portion weights were similar to those reported here ${ }^{(19)}$.

The data collected in this project can to be used to develop children's portion size assessment tools such as photographs and interactive computer software packages. The typical median and percentile information on these typical portion weights have already been used in developing and validating concise, simple tools to assess dietary intake of large groups of primary schoolchildren living in the UK (funded by the Foods Standards Agency and the Department of Health). Furthermore, a set of food photographs for children of different ages, based on portion weights supplied by this project, has been tested at the University of Newcastle ${ }^{(20,21)}$. This pilot work found that, at least for the limited range of foods tested, that providing children with images depicting age-appropriate portion sizes enabled them to estimate portions (as served) with accuracy approaching that of adults. This set of food photographs should form a complementary tool to the Photographic Atlas of Food Portion Sizes ${ }^{(2)}$ produced for use with adults. The data will also be useful in dietary assessment for the NDNS rolling programme. In order to reduce respondent burden the new rolling programme ${ }^{(22)}$ is moving away from the weighed intake method and pilot work is currently testing $24 \mathrm{~h}$ recall and unweighed diary methods. Both these methods require respondents (including children) to estimate the quantities they consume rather than weigh them. Tools to help adults estimate portion sizes are available but tools for children are urgently needed (Food Standards Agency, personal communication) and at the time of writing are about to be developed.

The data used in the present study were derived from the NDNS, which is the major dietary survey which influences nutrition policy in the UK. The results from this survey are used by government and it is clearly important that data that can be of benefit to the wider scientific community are fully and appropriately used. It is recognised that this type of survey has limitations but it remains the largest survey of its type in the UK (and indeed Europe), it is more representative of age, sex and region than anything else that has been or is currently available. In this respect, the survey is a unique source of weighed data on food portions and is not dependent on conceptualisation of food portions, food photographs or indeed estimates derived from adult weights. Many of the food model and photograph estimation aids used in the past were based on adult portion sizes (which are in themselves open to wide variation and possibly even greater subjective bias as concerns over obesity rise). This survey provides an evidence base of actual measured food portions and therefore circumnavigates vested interests that may wish to suggest 'ideal' portion sizes (as depicted on some labels). There is no doubt that portions sizes are changing and that actual measured data will provide a benchmark for a given time frame but at the very least they set parameters for possible ranges, many of which could not even have been imagined 30 years previously. 
NS British Journal of Nutrition

Table 2. Portion sizes (g) and $95 \%$ confidence intervals of a variety of foods consumed by children aged 7-10,11-14 and 15-18 years predicted from linear regression equations

\begin{tabular}{|c|c|c|c|c|c|c|c|c|c|}
\hline \multirow{2}{*}{$\begin{array}{l}\text { Age range (years)... } \\
\text { Food group }\end{array}$} & \multicolumn{3}{|c|}{$7-10(n 481)$} & \multicolumn{3}{|c|}{$11-14(n 475)$} & \multicolumn{3}{|c|}{$15-18(n 387)$} \\
\hline & $n$ & Predicted weight & $95 \% \mathrm{Cl}$ & $n$ & Predicted weight & $95 \% \mathrm{Cl}$ & $n$ & Predicted weight & $95 \% \mathrm{Cl}$ \\
\hline \multicolumn{10}{|l|}{ Pasta and rice } \\
\hline Pasta, boiled & 176 & 130 & 126,134 & 165 & 166 & 160,171 & 161 & 202 & 194, 209 \\
\hline Pasta, canned in sauce & 172 & 137 & 132,142 & 96 & 165 & 157,174 & 57 & 195 & 183,207 \\
\hline Rice, boiled & 137 & 116 & 112,121 & 146 & 149 & 143,155 & 124 & 183 & 175,192 \\
\hline \multicolumn{10}{|l|}{ Pizza } \\
\hline Pizza, thin base & 167 & 120 & 114,126 & 149 & 152 & 144,159 & 103 & 185 & 173,196 \\
\hline \multicolumn{10}{|l|}{ Other cereals } \\
\hline Yorkshire pudding & 114 & 48 & 45,50 & 104 & 57 & 54,61 & 104 & 68 & 63,73 \\
\hline \multicolumn{10}{|l|}{ Breads } \\
\hline Bread, white and softgrain, sliced & 405 & 58 & 57,59 & 385 & 71 & 70,72 & 310 & 85 & 83,86 \\
\hline Bread wholemeal, brown and granary, sliced & 128 & 56 & 54,57 & 109 & 68 & 66,71 & 108 & 81 & 78,85 \\
\hline Bread, white and softgrain, toasted & 304 & 46 & 45,47 & 289 & 56 & 55,58 & 224 & 67 & 65,69 \\
\hline Bread, rolls, white & 245 & 56 & 54,57 & 272 & 66 & 64,68 & 216 & 76 & 74,79 \\
\hline \multirow{2}{*}{\multicolumn{10}{|c|}{ Breakfast cereals }} \\
\hline & & & & & & & & & \\
\hline Rice Krispie-type cereals & 163 & 34 & 33,35 & 127 & 43 & 41,44 & 63 & 51 & 49,54 \\
\hline Flake cereals & 134 & 35 & 34,36 & 139 & 43 & 41,45 & 93 & 52 & 49,54 \\
\hline Coated cornflakes & 142 & 41 & 40,42 & 101 & 51 & 49,53 & 54 & 62 & 59,65 \\
\hline Weetabix & 111 & 34 & 33,35 & 95 & 40 & 39,42 & 57 & 47 & 45,50 \\
\hline \multicolumn{10}{|l|}{ Biscuits } \\
\hline Chocolate biscuits, fully coated sandwich & 205 & 26 & 25,26 & 144 & 27 & 26,28 & 93 & 29 & 28,30 \\
\hline Sandwich biscuits & 137 & 30 & 29,32 & 83 & 37 & 35,39 & 52 & 44 & 41,47 \\
\hline Chocolate biscuits, fully coated biscuit only & 88 & 25 & 24,26 & 72 & 28 & 27,30 & 54 & 32 & 30,34 \\
\hline \multicolumn{10}{|l|}{ Yogurts, desserts and puddings } \\
\hline Yogurt & 169 & 122 & 119,125 & 143 & 129 & 125,133 & 96 & 136 & 131,142 \\
\hline Ice-cream & 212 & 74 & 71,76 & 166 & 84 & 81,87 & 95 & 95 & 90,100 \\
\hline \multicolumn{10}{|l|}{ Milk and cream } \\
\hline Milk on cereal & 410 & 131 & 129,133 & 385 & 158 & 155,161 & 244 & 185 & 181,190 \\
\hline Milk as a drink & 277 & 186 & 183,190 & 182 & 214 & 208,219 & 133 & 242 & 234,250 \\
\hline Milk in tea or coffee & 214 & 52 & 51,54 & 258 & 49 & 47,51 & 262 & 45 & 42,48 \\
\hline \multicolumn{10}{|l|}{ Cheese } \\
\hline Hard cheese & 269 & 32 & 31,33 & 274 & 38 & 37,39 & 235 & 44 & 42,46 \\
\hline Hard cheese on bread & 170 & 33 & 32,34 & 189 & 39 & 38,41 & 183 & 46 & 44,48 \\
\hline \multicolumn{10}{|l|}{ Eggs and egg dishes } \\
\hline Eggs, fried/poached & 107 & 54 & 52,56 & 126 & 60 & 58,63 & 109 & 67 & 63,71 \\
\hline Eggs, boiled & 113 & 54 & 52,56 & 91 & 58 & 55,61 & 58 & 62 & 57,66 \\
\hline \multicolumn{10}{|l|}{ Butter, margarine and spreads } \\
\hline Soft margarine and fat spreads & 418 & 9 & $8 \cdot 9,9 \cdot 2$ & 406 & 11 & $10 \cdot 7,11 \cdot 2$ & 325 & 13 & $12 \cdot 6,13 \cdot 2$ \\
\hline Butter & 132 & 10 & 9,10 & 117 & 12 & 11,12 & 112 & 14 & 13,15 \\
\hline \multicolumn{10}{|l|}{ Meat and meat products } \\
\hline Sausages & 260 & 64 & 62,65 & 225 & 74 & 71,76 & 157 & 84 & 81,89 \\
\hline Cooked chicken/turkey & 231 & 67 & 64,69 & 189 & 83 & 80,86 & 175 & 100 & 96,104 \\
\hline Ham & 213 & 33 & 31,34 & 204 & 39 & 37,41 & 154 & 46 & 43,49 \\
\hline Bacon & 133 & 37 & 35,39 & 145 & 44 & 41,47 & 107 & 52 & 48,56 \\
\hline Roast meat & 95 & 60 & 57,63 & 102 & 77 & 73,81 & 70 & 94 & 89,100 \\
\hline Sausage rolls & 115 & 71 & 68,75 & 91 & 81 & 76,86 & 56 & 91 & 84,98 \\
\hline Burgers & 112 & 65 & 62,68 & 109 & 80 & 76,85 & 66 & 96 & 90,102 \\
\hline Chicken/turkey slices & 85 & 33 & 30,35 & 100 & 42 & 39,44 & 75 & 50 & 47,54 \\
\hline Meat pies, including chicken & 95 & 114 & 110,119 & 93 & 142 & 136,147 & 76 & 169 & 161,178 \\
\hline
\end{tabular}


NS British Journal of Nutrition

\begin{tabular}{|c|c|c|c|c|c|c|c|c|c|}
\hline \multirow{2}{*}{$\begin{array}{l}\text { Age range (years)... } \\
\text { Food group }\end{array}$} & \multicolumn{3}{|c|}{$7-10(n 481)$} & \multicolumn{3}{|c|}{$11-14(n 475)$} & \multicolumn{3}{|c|}{$15-18(n 387)$} \\
\hline & $n$ & Predicted weight & $95 \% \mathrm{Cl}$ & $n$ & Predicted weight & $95 \% \mathrm{Cl}$ & $n$ & Predicted weight & $95 \% \mathrm{Cl}$ \\
\hline \multicolumn{10}{|l|}{ Fish } \\
\hline Oily fish, canned & 93 & 47 & 44,50 & 92 & 57 & 54,61 & 85 & 68 & 63,72 \\
\hline Oily fish, canned on bread & 75 & 45 & 42,48 & 71 & 54 & 50,58 & 64 & 64 & 59,70 \\
\hline \multicolumn{10}{|l|}{ Vegetables } \\
\hline Carrots, raw & 82 & 39 & 36,41 & 62 & 45 & 42,49 & 60 & 52 & 47,58 \\
\hline Cucumber, raw & 180 & 26 & 24,27 & 195 & 28 & 26,30 & 167 & 31 & 28,34 \\
\hline Tomatoes, raw & 158 & 37 & 36,39 & 178 & 43 & 41,45 & 196 & 48 & 45,51 \\
\hline Lettuce, raw & 148 & 20 & 19,21 & 190 & 24 & 22,25 & 187 & 28 & 26,30 \\
\hline Baked beans in tomato sauce & 286 & 97 & 94,100 & 265 & 119 & 115,122 & 192 & 141 & 135,146 \\
\hline Carrots, boiled & 264 & 45 & 44,46 & 241 & 56 & 54,57 & 200 & 67 & 64,69 \\
\hline Peas/mixed vegetables, boiled & 221 & 43 & 42,45 & 206 & 54 & 52,56 & 146 & 66 & 63,69 \\
\hline Broccoli, boiled & 114 & 48 & 45,50 & 94 & 61 & 58,64 & 91 & 75 & 70,79 \\
\hline Sweetcorn, boiled & 118 & 50 & 48,53 & 83 & 63 & 59,67 & 84 & 76 & 70,82 \\
\hline Cauliflower, boiled & 91 & 56 & 53,59 & 73 & 72 & 68,76 & 66 & 88 & 82,93 \\
\hline \multicolumn{10}{|l|}{ Potatoes } \\
\hline Potato chips & 425 & 111 & 109,113 & 412 & 137 & 135,140 & 333 & 165 & 161,168 \\
\hline Roast potatoes & 191 & 94 & 91,97 & 191 & 123 & 118,127 & 151 & 152 & 145,158 \\
\hline Potatoes, old, boiled & 162 & 111 & 108,115 & 144 & 140 & 135,145 & 125 & 170 & 163,177 \\
\hline Potatoes, new, boiled & 153 & 104 & 101,108 & 128 & 134 & 128,139 & 97 & 163 & 156,171 \\
\hline Potatoes, old, mashed & 156 & 124 & 120,129 & 130 & 158 & 152,164 & 80 & 193 & 184,202 \\
\hline Potatoes, old, baked, weighed with skin & 119 & 139 & 134,145 & 134 & 169 & 163,176 & 119 & 200 & 191,210 \\
\hline \multicolumn{10}{|l|}{ Fruit } \\
\hline Apples, eating, weighed with skin and core & 257 & 93 & 92, 95 & 206 & 106 & 103,109 & 145 & 119 & 115,123 \\
\hline Bananas, flesh only & 204 & 86 & 85,88 & 149 & 95 & 93,98 & 128 & 105 & 101,109 \\
\hline \multicolumn{10}{|l|}{ Fruit juice } \\
\hline Fruit juice & 236 & 165 & 161,168 & 222 & 192 & 187, 197 & 173 & 220 & 213,227 \\
\hline \multicolumn{10}{|l|}{ Sugar and preserves } \\
\hline Sugar, white & 287 & 7 & $6 \cdot 9,7 \cdot 3$ & 300 & 9 & $8 \cdot 4,9 \cdot 0$ & 237 & 10 & $9 \cdot 9,10 \cdot 8$ \\
\hline Jam and marmalade & 175 & 17 & 16,18 & 118 & 21 & 20,22 & 81 & 25 & 24,27 \\
\hline \multicolumn{10}{|l|}{ Chocolate confectionery } \\
\hline Chocolate with/without addition & 210 & 31 & 30,32 & 191 & 36 & 35,38 & 132 & 42 & 40,45 \\
\hline Kit Kat & 176 & 28 & 27,29 & 148 & 31 & 30,32 & 83 & 34 & 32,36 \\
\hline Chocolate-covered caramel & 139 & 35 & 33,36 & 123 & 38 & 36,40 & 77 & 42 & 39,45 \\
\hline Chocolate-covered caramel biscuit & 97 & 41 & 39,42 & 93 & 46 & 44,48 & 58 & 52 & 49,55 \\
\hline \multicolumn{10}{|l|}{ Crisps and savoury snacks } \\
\hline Crisps & 383 & 26 & 26,27 & 362 & 28 & 27,29 & 274 & 30 & 29,31 \\
\hline Cereal-based snacks & 218 & 23 & 22,23 & 192 & 25 & 24,26 & 97 & 27 & 26,28 \\
\hline \multicolumn{10}{|l|}{ Savoury sauces and pickles } \\
\hline Gravy, thickened & 230 & 59 & 57,61 & 229 & 74 & 71,76 & 183 & 89 & 85,92 \\
\hline Tomato ketchup & 194 & 14 & 14,15 & 161 & 17 & 16,18 & 117 & 20 & 19,21 \\
\hline Mayonnaise & 128 & 13 & 13,14 & 121 & 15 & 14,16 & 157 & 18 & 16,17 \\
\hline \multicolumn{10}{|l|}{ Beverages } \\
\hline Tea, infusion & 199 & 149 & 146,152 & 233 & 182 & 178,185 & 225 & 215 & 210,220 \\
\hline Soft drinks, carbonated, not low energy & 352 & 241 & 237,245 & 385 & 286 & 281,291 & 306 & 333 & 325,340 \\
\hline Soft drinks, concentrated, not low energy & 269 & 48 & 47,49 & 205 & 57 & 56,59 & 137 & 67 & 64,69 \\
\hline Soft drinks, concentrated, low energy & 260 & 47 & 46,49 & 212 & 58 & 56,59 & 102 & 68 & 66,71 \\
\hline Soft drinks, carbonated, low energy & 214 & 221 & 215,226 & 216 & 261 & 255,268 & 160 & 303 & 293,312 \\
\hline Soft drinks, still, reconstituted & 163 & 220 & 215,225 & 144 & 236 & 228,244 & 60 & 253 & 241,264 \\
\hline
\end{tabular}




\section{Acknowledgements}

The present study was funded by the Food Standards Agency (project no. NO8018). The NDNS data were obtained from the Data Archive (University of Essex; http://www.data-archive. ac.uk). K. L. B. and P. J. L. carried out the calculation of portion sizes under the direction of project leader W. L. W. and S. A. O. who provided statistical expertise. A. J. A. and A. P. were expert advisors to the project, and edited drafts of the paper. M. A. H. compiled the information for the final paper. A. P. and P. J. L. provided the weighed food diaries for the reanalysis. The authors are grateful to Professor Annie Anderson, Mrs Gillian Swan of the Food Standards Agency and the referees for their comments and suggestions for improvement. There are no personal or financial conflicts of interest.

\section{References}

1. Food Standards Agency (2001) Food Portion Sizes, 3rd ed. London: The Stationery Office.

2. Nelson M, Atkinson M \& Meyer J (1997) A Photographic Atlas of Food Portion Sizes. London: MAFF Publications.

3. Livingstone MBE \& Robson PJ (2000) Measurement of dietary intake in children. Proc Nutr Soc 59, 279-293.

4. Gregory JR, Collins DL, Davies PSW, Hughes JM \& Clarke PC (1995) National Diet and Nutrition Survey: Children Aged $1 \frac{1}{2}$ to $4 \frac{1}{2}$. Volume 1: Report of the Diet and Nutrition Survey. London: H.M. Stationery Office.

5. Gregory J \& Lowe S (2000) National Diet and Nutrition Survey: Young People Aged 4-18 Years. Volume 1: Report of the Diet and Nutrition Survey. London: The Stationery Office.

6. Department of Health (1991) Dietary Reference Values for Food Energy and Nutrients for the United Kingdom. Department of Health Report on Health and Social Subjects no. 41. London: H.M. Stationery Office.

7. Longbottom P, Wrieden WL \& Pine C (2002) Is there a relationship between the food intakes of Scottish $5 \frac{1}{2}$ to $8 \frac{1}{2}$ year olds and those of their mothers? J Hum Nutr Diet 15, 271-279.

8. Lietz G, Barton KL, Longbottom PJ \& Anderson AS (2002) Can the EPIC food-frequency questionnaire be used in adolescent populations? Public Health Nutr 5, 783-789.

9. Payne JA \& Belton NR (1992) Nutrient intake and growth in pre-school children. Comparison of energy intake and sources of energy with growth. J Hum Nutr Diet 5, 287-298.
10. Holland B, Unwin ID \& Buss DH (1989) Milk Products and Eggs, 4th Supplement to McCance and Widdowson's The Composition of Foods, 4th ed. Cambridge: The Royal Society of Chemistry.

11. Chan W, Brown J, Lee SM \& Buss DH (1995) Meat, Poultry and Game, 5th Supplement to McCance and Widdowson's The Composition of Foods, 4th ed. Cambridge: The Royal Society of Chemistry and MAFF.

12. Holland B, Unwin ID \& Buss DH (1992) Fruit and Nuts, 1st Supplement to McCance and Widdowson's The Composition of Foods, 5th ed. Cambridge: The Royal Society of Chemistry and MAFF.

13. Nelson M, Atkinson M \& Meyer J (1997) Food Portion Sizes. A User's Guide to the Photographic Atlas of Food Portion Sizes. London: MAFF Publications.

14. Barton KL, Wrieden WL, Longbottom PJ, Adamson AJ \& Ogston SA (2003) How accurate are standard children's food portion sizes for estimation of dietary intakes of children of different ages? Proc Nutr Soc 62, 85A.

15. Bland JM \& Altman DG (1986) Statistical methods for assessing agreement between two methods of clinical measurement. Lancet i, 307-310.

16. Gibson RS (2005) Principles of Nutritional Assessment, 2nd ed. New York: Oxford University Press.

17. Nielsen SJ \& Popkin BM (2003) Patterns and trends in food portion sizes, 1977-1998. J Amer Med Assoc 289, 450-453.

18. Young LR \& Nestle M (2003) Expanding portion sizes in the US marketplace: implications for nutrition counseling. $J \mathrm{Am}$ Diet Assoc 103, 231-234.

19. Mullarkey D, Johnson B \& Hackett A (2007) Portion size selection of fruits and vegetables by 9 - to 10 -year-old children in Liverpool. J Hum Nutr Diet 20, 459-466.

20. Foster E, Matthews J, Nelson M, Harris JM, Mathers JC \& Adamson AJ (2006) Accuracy of estimates of food portion size using food photographs - the importance of using ageappropriate tools. Public Health Nutr 9, 509-514.

21. Foster E, Matthews JNS, Lloyd J, Marshall L, Nelson M, Barton KL, Wrieden WL, Cornelissen P, Harris J \& Adamson AJ (2007) Children's estimates of food portion size: the development and evaluation of three portion size assessment tools for use with children. Br J Nutr (Epublication ahead of print version 15 August 2007).

22. Ashwell M, Barlow S, Gibson S \& Harris C (2006) National diet and nutrition surveys: the British experience. Public Health Nutr 9, 523-530. 